\title{
Genetic testing for bicuspid aortic valve
}

\author{
Yeltay Rakhmanov ${ }^{1}$, Paolo Enrico Maltese ${ }^{1 \star}$, Alice Bruson ${ }^{1}$, Tommaso Beccari ${ }^{2}$, Munis Dundar $^{3}$ \\ and Matteo Bertelli ${ }^{1,4}$
}

\begin{abstract}
Bicuspid aortic valve (BAV) is a congenital defect in which the aortic valve has two rather than three leaflets. In many patients valve function may be normal but valve decompensation may occur due to other associated congenital abnormalities and secondary valve and aortic complications. Decompensation manifests as stenosis or regurgitation and thoracic aortic aneurysm and dissection. Cystic medial necrosis plays an important role in the pathogenesis of BAV. Prevalence of BAV is estimated at 0.5-2.0\%. In children, $70-85 \%$ of stenotic aortic valves are bicuspid, compared to at least $50 \%$ in adults. BAV has autosomal dominant inheritance. This Utility Gene Test was developed on the basis of an analysis of the literature and existing diagnostic protocols. It is useful for confirming diagnosis, as well as for differential diagnosis, couple risk assessment and access to clinical trials.
\end{abstract}

Keywords: Bicuspid aortic valve, EBTNA UTILITY GENE TEST

'MAGI's Lab, Rovereto, Italy

2Department of Pharmaceutical Sciences, University of Perugia, Perugia, Italy

${ }^{3}$ Department of Medical Genetics, Erciyes University Medical School, Kayseri, Turkey

${ }^{4}$ MAGI Euregio, Bolzano, Italy

*Corresponding author: P. E. Maltese E-mail: paolo.maltese@assomagi.org

DOI: 10.2478/ebtj-2018-0042 (c) 2018 Authors. This work was licensed under the Creative Commons AttributionNonCommercial-NoDerivs 3.0 License.

\section{Bicuspid aortic valve}

(Other synonyms: Bicuspid aortic valve stenosis, aortic valve disease)

\section{General information about the disease}

Bicuspid (or bicommissural) aortic valve (BAV) describes an aortic valve with two rather than three leaflets. It is frequently an antecedent to aortic valve stenosis or insufficiency and is often associated with other cardiovascular malformations, including aortic root dilation (1). This malformation may have normal valve function but due to associated secondary valve and aortic complications, such as calcific aortic valve disease and aortic dilation, valve decompensation may occur (2). The consequences of this condition may have serious long term health risks including progressive aortic valve disease (stenosis or regurgitation) and thoracic aortic aneurysm and dissection (3). Cystic medial necrosis plays an important role in the pathogenesis of BAV, and is associated with increased metalloproteinase activity and apoptosis of vascular smooth muscle cells (4).

A prevalence of $0.5 \%$ to $2.0 \%$ has been estimated, making BAV the most common cardiovascular malformation in humans $(5,6)$. In children, $70-85 \%$ of stenotic aortic valves are bicuspid, compared to at least $50 \%$ in adults $(7,8)$. If there are no associated congenital defects or secondary pathologies, BAV functions well, unlike other types of left heart obstruction (coarctation and interrupted aortic arch).

Late cardiac complications due to BAV were approximately $40 \%$ at a mean age of 52 years in the Olmsted County study (9). Clinical features of Turner syndrome (e.g. short stature in females with webbed neck and broad chest) or Williams syndrome (e.g. elfin facies, mild retardation) associated with other malformations suggest the possibility of BAV. The most common abnormal heart sound with BAV is a systolic ejection click (10).

Diagnosis is based on clinical assessment to identify symptoms, echocardiogram, 
electrocardiogram, chest radiogram, integration of septal and color Doppler with two-dimensional echocardiography, angiography by retrograde femoral arterial catheterization and angio-NMR (nuclear magnetic resonance), spin-echo MR imaging, CT, diagnostic catheterization and genetic testing.

Differential diagnosis should consider aortic coarctation, interruption of the aortic arch and hypoplastic left heart syndrome.

BAV has autosomal dominant inheritance with incomplete penetrance and variable expressivity (3).

\section{Non-syndromic BAV $(3,11,12,13)$}

- Aortic valve disease 1 (AOVD1, OMIM disease 109730) NOTCH1 (OMIM gene 190198);

- Aortic valve disease 2 (AOVD2, OMIM disease 614823) SMAD6 (OMIM gene 602931);

- GATA5 (OMIM gene 611496);

- AXIN1 (OMIM gene 603816);

- NKX2-5 (OMIM gene 600584).

\section{Syndromic BAV (13-15)}

- Marfan syndrome (MFS, OMIM disease 154700) - FBN1 (OMIM gene 134797);

- Loeys-Dietz syndrome 1,2 and 4 (LDS1, LDS2 and LDS4, OMIM diseases: 609192, 610168 and 614816) - TGFBR1 (OMIM gene 190181), TGFBR2 (OMIM gene 190182), TGFB2 (OMIM gene 190220);

- Andersen-Tawil syndrome (ATS, OMIM disease 170390) KCNJ2 (OMIM gene 600681);

- Aortic aneurysm, familial thoracic 6 (AAT6, OMIM disease 611788) - ACTA2 (OMIM gene 102620).

Other likely candidate genes for $\operatorname{BAV}(12,14,16)$

AXIN2 (OMIM gene 604025), EGFR (OMIM gene 131550), ELN (OMIM gene 130160), ENG (OMIM gene 131195), FGF8 (OMIM gene 600483), FLT1 (OMIM gene 165070), FN1 (OMIM gene 135600), GATA4 (OMIM gene 600576), GATA6 (OMIM gene 601656) (17), GLI1 (OMIM gene 165220), JAG1 (OMIM gene 601920), MCTP2 (OMIM gene 616297), MMP9 (OMIM gene 120361), MSX1 (OMIM gene 142983), NFATC1 (OMIM gene 600489), NOS1 (OMIM gene 163731), NOS3 (OMIM gene 163729), NOTCH2 (OMIM gene 600275), NOTCH3 (OMIM gene 600276), PAX6 (OMIM gene 607108), PDIA2 (OMIM gene 608012), PIGF (OMIM gene 600153), PPP3CA (OMIM gene 114105), PTCH1 (OMIM gene 601309), PTCH2 (OMIM gene 603673), SLC35B2 (OMIM gene 610788), SNAI3 (OMIM gene 612741), SOX9 (OMIM gene 608160), TBX5 (OMIM gene 601620), UFD1L (OMIM gene 601754), VEGFB (OMIM gene 601398), VEGFC (OMIM gene 601528), WNT4 (OMIM gene 603490) and ZNF236 (OMIM gene 604760).

Other research associates ZEB2 (OMIM gene 605802) with a complex syndrome manifesting with intellectual disability, facial dysmorphia, speech delay, hydronephrosis, bicuspid aortic valve and absence of corpus callosum (18) and MATR3 (OMIM gene 164015) with bicuspid aortic valve, aortic coarctation and patent ductus arteriosus (19).

Pathogenic variants may include missense, nonsense, splicing, small indels, small insertions and deletions, gross insertions and deletions, and complex rearrangements.

\section{Aims of the test}

- To determine the gene defect responsible for the disease;

- To confirm clinical diagnosis;

- To assess the recurrence risk and perform genetic counselling for at-risk/affected individuals.

\section{Test characteristics}

\section{Specialist centers/ Published Guidelines}

The test is listed in the Orphanet database and is offered by 12 accredited medical genetic laboratories in the EU, and in the GTR database, offered by 1 accredited medical genetic laboratories in the US.

Guidelines for clinical use of the test are described in "Genetics Home Reference" (ghr.nlm.nih.gov).

\section{Test strategy}

Clinically distinguishable syndromes can be analyzed by sequencing only those genes known to be associated with that specific disease using Sanger or Next Generation Sequencing (NGS); if the results are negative, or more generally if clinical signs are ambiguous for diagnosis, a multi-gene NGS panel is used to detect nucleotide variations in coding exons and flanking introns of the above genes.

Potentially causative variants and region with low coverage are Sanger-sequenced. Sanger sequencing is also used for family segregation studies.

Multiplex Ligation Probe Amplification (MLPA) is used to detect duplications and deletions in FBN1, NKX2-5, TGFBR1 and KCNJ2.

To perform molecular diagnosis, a single sample of biological material is normally sufficient. This may be $1 \mathrm{ml}$ peripheral blood in a sterile tube with $0.5 \mathrm{ml} \mathrm{K}$ EDTA or $1 \mathrm{ml}$ saliva in a sterile tube with $0.5 \mathrm{ml}$ ethanol $95 \%$. Sampling rarely has to be repeated.

Gene-disease associations and the interpretation of genetic variants are rapidly developing fields. It is therefore possible that the genes mentioned in this note may change as new scientific data is acquired. It is also possible that genetic variants today defined as of "unknown or uncertain significance" may acquire clinical importance.

\section{Genetic test results}

\section{Positive}

Identification of pathogenic variants in the above genes confirms the clinical diagnosis and is an indication for family studies.

A pathogenic variant is known to be causative for a given genetic disorder based on previous reports or predicted to be causative based on the loss of protein function or expected significant damage to protein or protein/protein interactions. In 
this way it is possible to obtain a molecular diagnosis in new/ other subjects, establish the risk of recurrence in family members and plan preventive and/or therapeutic measures.

\section{Inconclusive}

Detection of a variant of unknown or uncertain significance (VUS): a new variation without any evident pathogenic significance or a known variation with insufficient evidence (or with conflicting evidence) to indicate it is likely benign or likely pathogenic for a given genetic disorder. In these cases, it is advisable to extend testing to the patient's relatives to assess variant segregation and clarify its contribution. In some cases, it could be necessary to perform further examinations/tests or to do a clinical reassessment of pathological signs.

\section{Negative}

The absence of variations in the genomic regions investigated does not exclude a clinical diagnosis but suggests the possibility of:

- alterations that cannot be identified by sequencing, such as large rearrangements that cause loss (deletion) or gain (duplication) of extended gene fragments;

- sequence variations in gene regions not investigated by this test, such as regulatory regions (5' and 3' UTR) and deep intronic regions;

- variations in other genes not investigated by the present test.

\section{Unexpected}

Unexpected results may emerge from the test, for example information regarding consanguinity, absence of family correlation or other genetically based diseases.

\section{Risk for progeny}

In autosomal dominant transmission, the probability that an affected carrier transmit the variant to his/her children is $50 \%$ in any pregnancy, irrespective of the sex of the child conceived.

Incomplete penetrance and/or variable expressivity may influence the manifestation of clinical symptoms in individuals harboring a disease-causing variation.

\section{Limits of the test}

The test is limited by current scientific knowledge regarding the gene and disease.

Analytical sensitivity (proportion of positive tests when the genotype is truly present) and specificity (proportion of negative tests when the genotype is not present)

NGS Analytical sensitivity $>99.99 \%$, with a minimum coverage of 10X; Analytical specificity $99.99 \%$.

SANGER Analytical sensitivity $>99.99 \%$; Analytical specificity 99.99\%.

MLPA Analytical sensitivity $>99.99 \%$; Analytical specificity $99.99 \%$.
Clinical sensitivity (proportion of positive tests if the disease is present) and clinical specificity (proportion of negative tests if the disease is not present)

Clinical sensitivity: the variations in the aforementioned genes are associated with BAV, but in many cases, these are individual variations (identified in one or few families) and total epidemiological data is therefore not available. Clinical sensitivity will be estimated based on internal cases (20).

Clinical specificity: data not available.

\section{Prescription appropriateness}

The genetic test is appropriate when:

a) the patient meets the diagnostic criteria for $\mathrm{BAV}$;

b) the sensitivity of the test is greater than or equal to that of tests described in the literature.

\section{Clinical utility}

Clinical management

Utility

Confirmation of clinical diagnosis

Yes

Differential diagnosis Yes

Couple risk assessment Yes

Availability of clinical trials can be checked on-line at https://clinicaltrials.gov/

\section{References}

1. Cripe L, Andelfinger G, Martin LJ, Shooner K, Benson DW. Bicuspid aortic valve is heritable. J Am Coll Cardiol 2004; 7;44(1): 138-43.

2. Atkins SK, Sucosky P. Etiology of bicuspid aortic valve disease: Focus on hemodynamics. World Journal of Cardiology 2014; 6(12): 1227-33.

3. Freeze SL, Landis BJ, Ware SM, Helm BM. Bicuspid Aortic Valve: a Review with Recommendations for Genetic Counseling. Journal of genetic counseling 2016; 25(6): 1171-78.

4. Braverman AC, Güven H, Beardslee MA, Makan M, Kates AM, Moon MR. The bicuspid aortic valve. Curr Probl Cardiol 2005; 30(9): 47022.

5. Roberts WC. The congenitally bicuspid aortic valve. A study of 85 autopsy cases. Am J Cardiol 1970; 26(1): 72-83.

6. Steinberger J, Moller JH, Berry JM, Sinaiko AR. Echocardiographic diagnosis of heart disease in apparently healthy adolescents. Pediatrics 2000; 105(4 Pt 1): 815-18.

7. Mack G, Silberbach M. Aortic and pulmonary stenosis. Pediatr Rev 2000; 21: 79-85.

8. Ward C. Clinical significance of the bicuspid aortic valve. Heart 2000; 83(1): 81-85.

9. Michelena HI, Desjardins VA, Avierinos JF, Russo A, Nkomo VT, Sundt TM, Pellikka PA, Tajik AJ, Enriquez-Sarano M. Natural history of asymptomatic patients with normally functioning or minimally dysfunctional bicuspid aortic valve in the community. Circulation 2008; 117(21): 2776-84.

10. Zuberbuhler JR. Aortic stenosis. Clinical Diagnosis in Pediatric Cardiology. London, England: Churchill Livingstone 1981; 75-82.

11. Qu XK, Qiu XB, Yuan F, Wang J, Zhao CM, Liu XY, Zhang XL, Li RG, Xu YJ, Hou XM ,Fang WY, Liu X, Yang YQ. A novel NKX2.5 lossof-function mutation associated with congenital bicuspid aortic valve. Am J Cardiol 2014; 15;114(12): 1891-95. 
12. Bonachea EM, Zender G, White P, Corsmeier D, Newsom D, Fitzgerald-Butt S, Garg V, McBride KL. Use of a targeted, combinatorial next-generation sequencing approach for the study of bicuspid aortic valve. BMC Med Genomics 2014; 26; 7:56.

13. Abdulkareem N, Smelt J, Jahangiri M. Bicuspid aortic valve aortopathy: genetics, pathophysiology and medical therapy. Interact Cardiovasc Thorac Surg 2013; 17(3): 554-59.

14. Giusti B, Sticchi E, De Cario R, Magi A, Nistri S, Pepe G. Genetic Bases of Bicuspid Aortic Valve: The Contribution of Traditional and High-Throughput Sequencing Approaches on Research and Diagnosis. Front Physiol 2017; 8: 612.

15. Prakash SK, Bossé $Y$, Muehlschlegel JD, Michelena HI, Limongelli G, Della Corte A, Pluchinotta FR, Russo MG, Evangelista A, Benson DW,Body SC, Milewicz DM; BAVCon Investigators. A roadmap to investigate the genetic basis of bicuspid aortic valve and its complications: insights from the International BAVCon (Bicuspid Aortic Valve Consortium). J Am Coll Cardiol 2014; 64(8): 832-39.

16. Girdauskas E, Geist L, Disha K, Kazakbaev I, Groß T, Schulz S, Ungelenk M, Kuntze T, Reichenspurner H, Kurth I. Genetic abnormalities in bicuspid aortic valve root phenotype: preliminary results. Eur J Cardiothorac Surg 2017; 52(1): 156-62.
17. Lin X, Huo Z, Liu X, Zhang Y, Li L, Zhao H, Yan B, Liu Y, Yang Y, Chen YH. A novel GATA6 mutation in patients with tetralogy of Fallot or atrial septal defect. J Hum Genet 2010; 55(10): 662-67.

18. Bowling KM, Thompson ML, Amaral MD, Finnila CR, Hiatt SM, Engel KL, Cochran JN, Brothers KB, East KM, Gray DE, Kelley WV, Lamb NE, Lose EJ, Rich CA, Simmons S, Whittle JS, Weaver BT, Nesmith AS, Myers RM, Barsh GS, Bebin EM, Cooper GM. Genomic diagnosis for children with intellectual disability and/or developmental delay. Genome Med 2017; 9(1): 43.

19. Quintero-Rivera F, Xi QJ, Keppler-Noreuil KM, Lee JH, Higgins AW, Anchan RM, Roberts AE, Seong IS, Fan X, Lage K, Lu LY, Tao J, Hu X,Berezney R, Gelb BD, Kamp A, Moskowitz IP, Lacro RV, Lu W , Morton CC, Gusella JF, Maas RL. MATR3 disruption in human and mouse associated with bicuspid aortic valve, aortic coarctation and patent ductus arteriosus. Hum Mol Genet 2015; 24(8): 2375-89.

20. Chen B, Gagnon M, Shahangian S, Anderson NL, Howerton DA, Boone JD; Centers for Disease Control and Prevention (CDC). Good Laboratory Practices for Molecular Genetic Testing for Heritable Diseases and Conditions. MMWR Recomm Rep 2009; 58 (RR-6): 1-29. 